\title{
Iron fertilization in the glacial ocean
}

Alfredo Martínez-García' and Gisela Winckler²

We review the hypothesis that the increased supply of iron-bearing dust to high-nutrient, low-chlorophyll regions of the ocean stimulated phytoplankton blooms that sequestered climatically relevant amounts of carbon and contributed to lowering atmospheric $\mathrm{CO}_{2}$ during ice ages.

The concentration of major inorganic nutrients nitrate and phosphate is perennially high in one quarter of the surface ocean. However, despite this excess in macronutrients available for phytoplankton growth, biomass production still remains fairly low in the Southern Ocean, the equatorial Pacific and the subarctic North Pacific.

The causes of the incomplete use of macronutrients by marine organisms and hence of the existence of these high-nutrient, low-chlorophyll (HNLC) regions have been subject to intense oceanographic research in the past decades. In the late eighties John $\mathrm{H}$. Martin and his team reported evidence suggesting that phytoplankton growth in these regions was chronically limited by iron deficiency (Martin and Fitzwater 1988; Martin et al. 1990). Martin immediately realized that one important consequence of this discovery was that changes in the availability of $\mathrm{Fe}$ in $\mathrm{HNLC}$ regions could have large effects on marine phytoplankton productivity and organic carbon export to the subsurface ocean, and therefore could influence the efficiency of the global biological pump in sequestering atmospheric $\mathrm{CO}_{2}$ (Martin and Fitzwater 1988).

\section{Iron fertilization in the Southern Ocean}

The Southern Ocean is the largest HNLC region (Fig. 1) and represents the area of the ocean where variations in iron availability can have the largest impact on Earth's carbon cycle through its fertilizing effect on marine ecosystems. In 1984, several years before Martin's discovery of iron limitation, a series of papers postulated the potential role of the Southern Ocean in driving changes in atmospheric $\mathrm{CO}_{2}$ concentrations during ice ages (Knox and McElroy 1984; Sarmiento and Toggweiler 1984; Siegenthaler and Wenk 1984). Combining these ideas with his discovery of iron limitation in the modern Southern Ocean, and the first observations of increased glacial dust deposition recorded in Antarctic ice cores, Martin proposed that the enhanced supply of $\mathrm{Fe}$ from dust could have stimulated marine productivity during ice ages, increasing carbon sequestration in the deep ocean and leading to a decrease in atmospheric $\mathrm{CO}_{2}$ levels (Martin 1990).

\section{Iron enrichment experiments}

Since the seminal work of Martin, the effect of iron on marine ecosystem structure and productivity has been extensively studied through a series of short-term in situ iron enrichment experiments performed in the different HNLC regions of the ocean, but also by observing phytoplankton blooms induced by natural iron fertilization (Fig. 1).

Artificial iron fertilization experiments have provided unambiguous evidence that iron addition generates phytoplankton blooms in HNLC regions (Boyd et al. 2007; Smetacek et al. 2012). These findings are consistent with the observations of natural phytoplankton blooms in these regions stimulated by $\mathrm{Fe}$

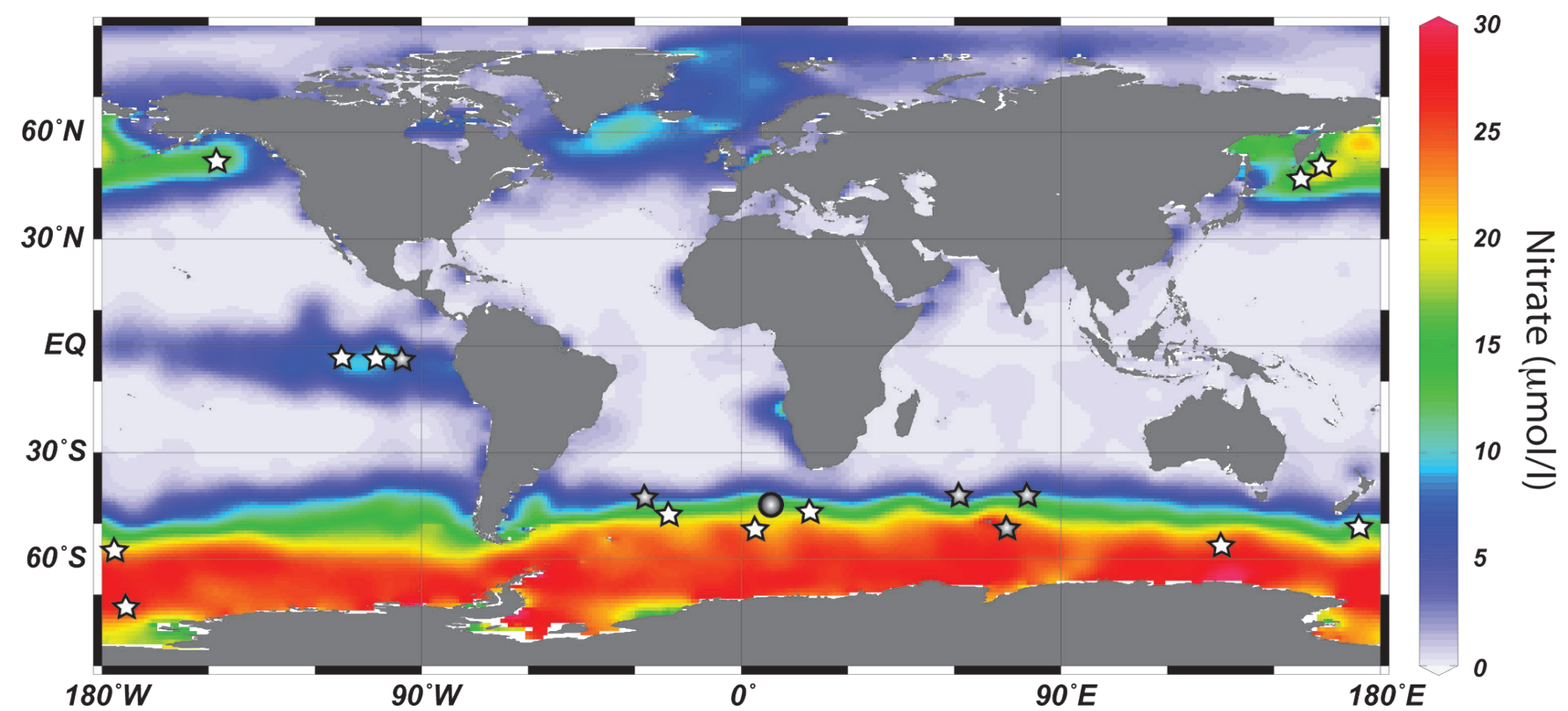

Figure 1: World ocean surface nitrate concentrations from the World Ocean Atlas (Garcia et al. 2010) indicating the three high-nutrient, low-chlorophyll (HNLC) areas (Southern Ocean, equatorial Pacific, Subarctic North Pacific). The gray circle marks the location of ODP Site 1090 and the stars mark locations where iron fertilization experiments (white stars) and iron enrichment experiments (gray stars) have been performed (Blain et al. 2007; Boyd et al. 2007; Smetacek et al. 2012). 
input from different sources including continental dust (Cassar et al. 2007), volcanic ash (Hamme et al. 2010), free-drifting icebergs (Smith et al. 2007) and the upwelling of ironrich deep waters (Blain et al. 2007). However, the efficiency of the iron fertilization process in removing $\mathrm{CO}_{2}$ from the atmosphere ultimately depends on the depth at which sinking organic matter is remineralized. For example, in the Southern Ocean, the fraction of carbon retained within the deep winter mixed layer (upper $200 \mathrm{~m}$ ) would return to the atmosphere within months, but organic matter sinking to the deep ocean and sediments, could be sequestered for centuries, millennia or longer (Smetacek et al. 2012). Unfortunately, the results of iron fertilization studies in the modern ocean with respect to the efficiency of organic carbon export to the deep ocean are still ambiguous, limiting our understanding of the potential efficiency of large-scale iron fertilization for atmospheric $\mathrm{CO}_{2}$ sequestration.

\section{Paleoceanographic records}

Paleoceanographic studies provide an excellent opportunity to directly test the influence of continued large-scale iron fertilization on marine phytoplankton production and downward export of biomass, and its potential effect on atmospheric $\mathrm{CO}_{2}$ levels.

Paleoceanographic reconstructions attempting to test the iron hypothesis have mainly focused on the Southern Ocean. Data indicate a heterogeneous response of Southern Ocean productivity during ice ages,

characterized by an increase in productivity in the Subantarctic zone and a decrease in the Antarctic zone (Kohfeld et al. 2005). The decrease in Antarctic zone productivity was first interpreted as a challenge to the iron hypothesis raising doubts about the sensitivity of marine ecosystems to atmospheric iron supply (Mortlock et al. 1991). However, subsequent studies have proposed that the Antarctic Ocean was more strongly stratified during ice ages, reducing major nutrient supply from upwelling waters, and consequently explaining the lower glacial marine productivity in the Antarctic zone of the Southern Ocean (Francois et al. 1997).

In addition, in the Subantarctic zone, which is located downwind of major Southern Hemisphere dust sources, several studies have indeed found a remarkable correlation between iron deposition and marine productivity as predicted by the iron fertilization hypothesis (Kohfeld et al. 2005; Kumar et al. 1995; Martínez-García et al. 2009). The productivity increase occurred consistently in the later part of the glacial cycle, when atmospheric $\mathrm{CO}_{2}$ concentrations were below a threshold of about $225 \mathrm{ppm}$ and dust fluxes peaked (Kohfeld et al. 2005; Martínez-García et al. 2009). In addition, a recent study has shown that in the Subantarctic Atlantic (ODP Site 1090; Fig. 1) the high dust and productivity intervals of the last ice age are also characterized by an increase in the degree of nitrate consumption by marine phytoplancton, a combination that is only consistent with iron fertilization (Martínez-García et al. 2014).

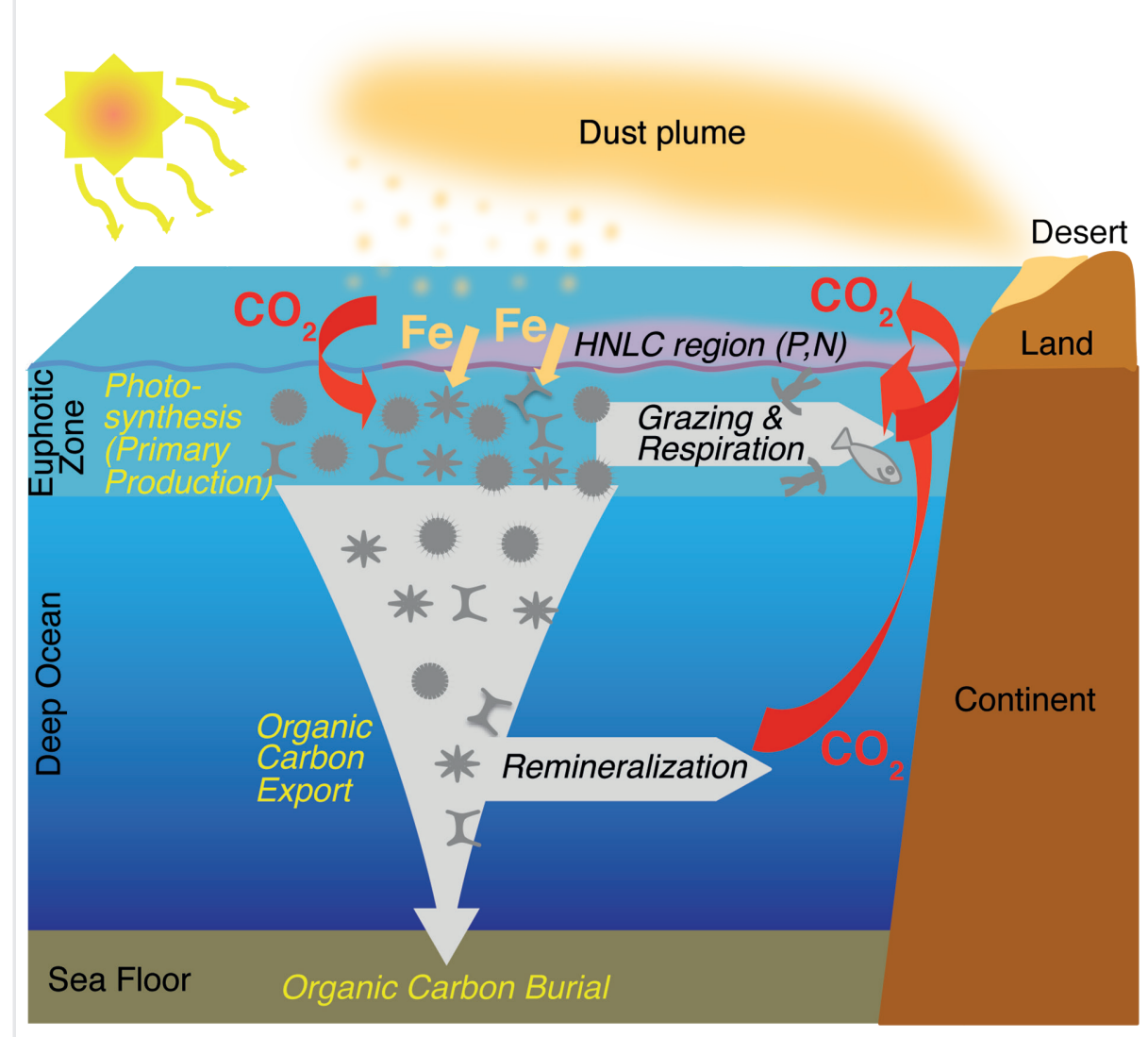

Figure 2: Schematic representation of the iron fertilization process.

These findings suggest that the iron fertilization process in the Subantarctic Southern Ocean may have been particularly important to explain the last 40 ppmv of the atmospheric $\mathrm{CO}_{2}$ decrease observed during the ice age cycles of the last million of years (e.g. Martínez-García et al. 2011; Martínez-García et al. 2014). In fact, a $\mathrm{CO}_{2}$ drawdown of up to 40 ppmv from Subantarctic iron fertilization is consistent with estimates obtained using geochemical box models and Earth system models, which in most cases range between 20 and 40 ppmv (e.g. Hain et al. 2010; Brovkin et al. 2007). In addition, recent studies suggest that dust flux, productivity and nutrient consumption also increased during the Antarctic millennial-scale cold events that characterize the last ice age (Martínez-García et al. 2014; Anderson et al 2014). These findings indicate that iron fertilization can also contribute to explain the millennial-scale $\mathrm{CO}_{2}$ oscillations associated with these Antarctic cold events.

Although reconstructions of the effect of iron fertilization in the Southern Ocean have, so far, been largely limited to the Atlantic sector of the Southern Ocean, new sediment cores and dust flux reconstructions from the Pacific sector of the Southern Ocean (Lamy et al. 2014) will soon allow the hypothesis to be tested also in the South Pacific, the largest subbasin of the southern Ocean.

\section{Implications for the future}

Paleoceanographic data and models suggest that iron fertilization of the Subantarctic zone of the Southern Ocean stimulated marine export production and that this process increased carbon sequestration into the deep ocean, contributing to explain part of the atmospheric $\mathrm{CO}_{2}$ decrease observed during ice age cycles. However, its potential application as a geoengineering strategy to mitigate anthropogenic $\mathrm{CO}_{2}$ emissions is highly controversial, not only due to doubts about the limited efficiency of artificial iron fertilization for long-term atmospheric $\mathrm{CO}_{2}$ sequestration, but also because of the potentially dangerous side-effects of large scale iron addition such as deoxygenation of intermediate waters or changes in phytoplankton community composition that may cause toxic blooms or promote changes further along the marine food chain (e.g. Buesseler et al. 2004; Johnson and Karl 2002).

\section{AFFILIATIONS}

${ }^{1}$ Geological Institute, ETH Zurich, Switzerland 'Lamont-Doherty Earth Observatory, Columbia University, Palisades, USA and Department of Earth and Environmental Sciences, Columbia University, New York, USA

\section{CONTACT}

Alfredo Martínez-García: alfredo.martinez-garcia@erdw. ethz.ch

\section{REFERENCES}

Full reference list under:

www.pages-igbp.org/products/magazine/ref2014_2.pdf Boyd PW et al. (2007) Science 315: 612-617

Kohfeld KE et al. (2005) Science 308: 74-78 Lamy F et al. (2014) Science 343: 403-407 Martin JH (1990) Paleoceanography 5: 1-13 Martínez-García A et al. (2014) Science 343: 1347-1350 